\title{
Prevalence and characteristics of disabled children: findings from the 1974 General Household Survey
}

\author{
JANE WEALE AND JONATHAN BRADSHAW \\ From the Social Policy Research Unit, Department of Social Administration and Social Work, University of \\ York
}

SUMMARY In the absence of nationally representative data on the prevalence of disability among children, a special analysis of relevant data in the General Household Survey (GHS) was carried out. A long-standing illness, disability or infirmity was present in $7.6 \%$ of the children under 16 in the 1974 sample of the GHS. An assessment of the extent to which the children were disabled resulted in $10 \%$ of the children being classified as severe, $29 \%$ as moderate, and $61 \%$ as mild. About half of the children classified as severe had a congenital anomaly or suffered from a mental disorder. Prevalence rates for specific conditions were compared with those obtained in other studies. Compared with all children in the survey, significantly more of the severely and moderately disabled children were boys than girls, and significantly more came from the skilled manual socioeconomic groups. The proportion of lone parent families was not significantly different from that in the overall sample.

An estimate of the prevalence of disability in the adult population of Great Britain was provided in the national survey of the population carried out in 1969.' This survey did not cover children, and although studies have been carried out of the prevalence of disabilities among children in particular areas, and of particular disabilities or particular age groups, ${ }^{2-4}$ there has been no large-scale survey of the child population to establish national figures on the prevalence of disabilities and the characteristics of the affected children and their families. Disability is much less common among children than among adults and one major obstacle to a national survey is the very large number of households that would need to be screened in order to obtain a sample of severely disabled children that was large enough to permit subsample analyses.
A study of the impaired subsample of the 17000 children in the 1970 'British births' cohort' is now in progress and will provide detailed and nationally representative information on the prevalence of impairment among 10-year-old children and on the characteristics of the children and their families. In the absence of such a representative study, the data available from other sources were examined by this unit as part of its programme of research on the social policy aspects of child handicap. ${ }^{8}$ In this paper we present some findings on disability among children that were obtained from the first special analysis of such data in the General Household Survey (GHS). The terminology used in the paper is set out in the Figure, and there is a full description of the study in an unpublished paper obtainable from the Social Policy Research Unit. ${ }^{7}$

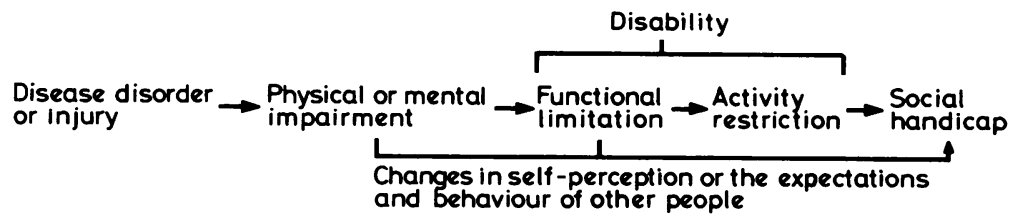

Figure Terminology of disablement.

The terminology of disablement has recently been reviewed. ${ }^{17}$ In this paper we use the terminology developed by Wood for the World Health Organisation ${ }^{18}$ as elaborated by Taylor, ${ }^{19}$ slightly amended so as to include mental impairment. This can be represented as shown in the Figure. A revised version of this terminology will shortly be published by WHO. 


\section{Method}

The GHS is a multipurpose survey which is carried out continuously and provides annual information on a nationally representative sample of the population of private households in Great Britain. The effective sample size varies a little from year to year. In 1974, the year used for this analysis, the effective sample consisted of about 14200 private households and interviews were obtained at $86 \%$ of these households. ${ }^{8}$ Throughout the period from 1971, when the survey started, to 1976 , all respondents with children under 16 answered a child health schedule which included questions on chronic sickness. In 1974 the first of these questions was 'Do any of your children under 16 have any long-standing illness, disability or infirmity?', followed by 'Does the complaint limit the child's activities in any way?'. This analysis is based on the group of households which answered 'Yes' to the first question. There were 579 such households and they contained a total of 653 affected children. The 1974 GHS data for this subsample of households were obtained from the Department of Health and Social Security after clearance with the Office of Population Censuses and Surveys who conduct the GHS on behalf of a number of Government departments.

The data from the GHS relating to disability and handicap among children have limitations, because the questions were not designed to provide information of this kind. The respondent, normally the parent, is the sole source of information about the child. He or she gives a full description of the type of long-standing illness (this term will be used as a shorthand for the full phrase in the question) affecting the child, the cause of the illness, and the medical term for it if this is known. There is thus no medical assessment of the nature of the complaint and the information obtained from respondents may not be complete or fully accurate. The information on the illness is coded by coders with some medical knowledge and experience who are able to assess the descriptions given and code them according to the International Classification of Diseases. ${ }^{9}$ No attempt is made however, to validate the accuracy of the information provided with hospital records or those of the school health service or the general practitioner. The respondent also provides information on the activity limitation caused by the long-standing illness, and information is available on the type of school attended by the child (in particular whether it is a special school or not).

In terms of the conceptual scheme of disablement set out in the Figure, the GHS provides reasonable data on the disease, disorder, or injury affecting the children, assuming that in the great majority of cases the information provided by the respondent is accurate. However, in the case of disorders where the nature of the impairment may vary according to the severity of the disorder or the parts of the body? affected (for example, spina bifida), it is not always? certain from the disease classification whether the child has a physical impairment alone or both a physical and a mental impairment. Only a limited amount of information is available on the extent of the disabilities affecting the child and there is no information on the severity of the handicap that results from these disabilities.

The size of the subsample of affected children $\overline{\bar{n}}$ (653) is also a limitation but it would be possible to increase its size by including later years in an analysis. In the absence of representative data from otheres sources, the GHS does provide information on what $\overrightarrow{0}$ is viewed by a national sample of families as chronicsickness among their children and some information $\omega$ on the severity of the disability caused by this sicknesscan be obtained. Because of the multipurpose nature? of the survey, a variety of socioeconomic data are alsow available and can be used to describe the characteristics of the affected children.

\section{Results}

PREVALENCE OF LONG-STANDING DISEASES DISORDERS AMONG CHILDREN UNDER 16 A MOST COMMON DISEASES OR DISORDERS FOU IN THE SAMPLE

A long-standing illness, disability, or infirmity wâs present in 633 of the 8292 children under 16 included in the 1974 GHS, a prevalence rate of $7 \cdot 6 \%$. Theres were also a further 20 cases classed as having ao long-standing illness in the survey but possibly⿳⺈. suffering only from an acute illness; because of the uncertainty these have been included as mild cases in $\overrightarrow{\hat{O}}$ most of the Tables, giving a total of 653 children Fifty-five of the children suffered from two complaints and a further seven from threeo complaints. Asthma was the most common complaint, affecting $14 \%$ of the children, followed byS infantile eczema $(9 \%)$, bronchitis $(9 \%)$, hay fever $(6 \%)$, and strabismus (6\%). Nearly half of the children in the subsample (44\%) were affected by one of these five complaints.

ASSESSMENT OF THE SEVERITY OF THE
DISABILITY RESULTING FROM TH
LONG-STANDING DISEASE OR DISORDER Many of the complaints affecting the children wouldo not give rise to severe disabilities. The survey provides information on whether the illness limits then child's activities in any way and on the extent to which the child is able to get out of the house. Table 1 shows 
Table 1 Relationship between activity limitation and restriction in getting out of the house

\begin{tabular}{|c|c|c|c|c|c|}
\hline & \multicolumn{3}{|c|}{ Complaint prevents child getting out of house } & \multirow{2}{*}{$\begin{array}{l}\text { Complaint does not } \\
\text { prevent child getting } \\
\text { out of house }\end{array}$} & \multirow[b]{2}{*}{ All cases in subsample } \\
\hline & Most of the time & Some of the time & Hardly ever & & \\
\hline $\begin{array}{l}\text { Complaint does limit child's activities in } \\
\text { some way }\end{array}$ & 19 & 100 & 51 & 108 & 278 \\
\hline $\begin{array}{l}\text { Complaint does not limit child's activities in } \\
\text { any way }\end{array}$ & 0 & 26 & 31 & 296 & 353 \\
\hline ALL CASES & 19 & 126 & 82 & 404 & $631^{*}$ \\
\hline
\end{tabular}

*Information not available for 22 cases.

the relationship between these two restrictions on the child's ability to live normally. The activities of 278 (44\%) of the children were limited by their complaints and a further 119 of these were restricted in getting out of the house most or some of the time.

Additional information was available on the length of time for which the complaint had been limiting activities, the child's age, the type of school attended (in particular whether it was a special school or not) and the $I C D$ coding for the long-standing illness. The advice was sought of a consultant paediatrician* with much experience of disability in children in order to assess the extent to which the children were likely to be disabled. By using his knowledge of the probable effects of the complaints affecting the children, and the available information on age and activity restriction, the children were classified as severely, moderately, or mildly disabled. The three groups were composed of 63,184 , and 406 children respectively.

TYPES OF COMPLAINT FOUND IN THE THREE SEVERITY GROUPS

Because of the limited amount of information available, all children at special schools were classed as severe although it was recognised that there is considerable variation between local education authorities in the criteria used for placing children in special schools. There were 33 children at special schools and about half of these suffered from some form of mental disorder. A further 30 children were also classed as severe, of whom 15 were at normal schools and 15 were too young for school or were at a day nursery. When all the children assessed as severely disabled were considered, 22 (35\%) had complaints in $I C D$ disease category XIV 'Congenital anomalies'; $12(19 \%)$ in the 'Mental disorders' category (V); and $7(11 \%)$ in the 'Diseases of the nervous system and sense organs' category (VI) (Table 2).

\footnotetext{
- Dr. Walter Henderson. Before his retirement Dr. Henderson was the consultant paediatrician for York and he is a medical adviser to the Family Fund.
}

The moderate classification was used where the illness caused some discomfort or difficulty and in most cases where the complaint had been present for some years and imposed some limitation on the child. Just under half of the children classed as moderate had complaints in ICD category VIII 'Diseases of the respiratory system' (Table 2 ).

The mild classification grouped together all the children who had a complaint which possibly caused some inconvenience or had an effect on the appearance but could not be considered to be disabling (although in some circumstances the complaint might give rise to some forms of 'social handicap'). The most common types of complaint in this group were also those in ICD category VIII 'Diseases of the respiratory system' and these affected $120(30 \%)$ of the mild group of children (Table 2).

PREVALENCE OF SEVERE DISABILITY AND OF SOME INDIVIDUAL CONDITIONS

Sixty-three children in the sample were classed as severely disabled, a prevalence rate of 7.6 per 1000 children under 16 (95\% confidence limits : $5 \cdot 7-9.5$ per 1000$)$. Prevalence rates for some individual conditions can also be derived from the GHS, although the rates are based on small numbers and are subject to large sampling errors; data from several years of the GHS would have to be aggregated to enable more reliable rates to be calculated.

\section{Mental impairment}

There were 35 children classified as severe who had either a mental impairment alone or both a mental and a physical impairment, giving a prevalence rate of $4 \cdot 2$ per 1000 children under 16 .

\section{Spina bifida}

Eight of the children classified as severe had spina bifida with or without hydrocephalus (ICD code 741) as did one of the children classified as moderate, so that the prevalence rate for severe and moderate was $1 \cdot 1$ per 1000 children under 16 . 
Table 2 Types of disorder found in each severity group

\begin{tabular}{|c|c|c|c|c|c|}
\hline \multirow{2}{*}{\multicolumn{2}{|c|}{ ICD disease category* }} & \multicolumn{3}{|c|}{ Nos. of children in each severity classification } & \multirow[b]{2}{*}{ All children in subsample } \\
\hline & & Severe & Moderate & Mild & \\
\hline $\mathbf{I}$ & Infective and parasitic diseases & 3 & 0 & 6 & 9 \\
\hline II & Neoplasms & 4 & 0 & 2 & 6 \\
\hline III & $\begin{array}{l}\text { Endocrine, nutritional and metabolic } \\
\text { diseases }\end{array}$ & c 1 & 9 & 11 & 21 \\
\hline IV & $\begin{array}{l}\text { Diseases of blood and blood-forming } \\
\text { organs }\end{array}$ & g 2 & 1 & 6 & 9 \\
\hline $\mathbf{v}$ & Mental disorders & 12 & 5 & 17 & 34 \\
\hline VI & $\begin{array}{l}\text { Diseases of the nervous system and } \\
\text { sense organs } \\
\text { - Strabismus (eye) } \\
\text { - Migraine } \\
\text { - Refractive errors (eye) }\end{array}$ & $\begin{array}{l}\text { d } \\
(-) \\
(-) \\
(-)\end{array}$ & $\begin{array}{l}25 \\
(-) \\
(12) \\
(-)\end{array}$ & $\begin{array}{l}76 \\
(32) \\
(4) \\
(12)\end{array}$ & $\begin{array}{l}108 \\
\quad(32) \\
(16) \\
(12)\end{array}$ \\
\hline VII & Diseases of the circulatory system & 1 & 1 & 8 & 10 \\
\hline VIII & $\begin{array}{l}\text { Diseases of the respiratory system } \\
\text {-Asthma } \\
\text { - Bronchitis, unqualified } \\
\text { - Hay fever }\end{array}$ & $\begin{array}{l}3 \\
(1) \\
(-) \\
(-)\end{array}$ & $\begin{array}{r}84 \\
(52) \\
(15) \\
(10)\end{array}$ & $\begin{array}{r}120 \\
(36) \\
(36) \\
(25)\end{array}$ & $\begin{array}{r}207 \\
(89) \\
(51) \\
(35)\end{array}$ \\
\hline IX & Diseases of the digestive system & 0 & 3 & 14 & 17 \\
\hline $\mathbf{x}$ & Diseases of the genitourinary system & n 2 & 3 & 6 & 11 \\
\hline XII & $\begin{array}{l}\text { Diseases of the skin and } \\
\text { subcutaneous tissue } \\
\text {-Infantile eczema }\end{array}$ & $\begin{array}{l}0 \\
(-)\end{array}$ & ${ }^{22}(16)$ & $\begin{array}{l}55 \\
(39)\end{array}$ & $\begin{array}{l}77 \\
(55)\end{array}$ \\
\hline XIII & $\begin{array}{l}\text { Diseases of the musculoskeletal } \\
\text { system and connective tissue }\end{array}$ & 1 & 5 & 7 & 13 \\
\hline XIV & $\begin{array}{l}\text { Congenital anomalies } \\
\text { - Other anomaly of lower limb }\end{array}$ & 22 & 15 & ${ }^{47}(10)$ & ${ }^{84}(13)$ \\
\hline $\mathrm{XV}$ & $\begin{array}{l}\text { Certain causes of perinatal morbidity } \\
\text { and mortality }\end{array}$ & $y_{2}$ & 1 & 6 & 9 \\
\hline $\begin{array}{r}\text { XVI } \\
\text { XVII(N) }\end{array}$ & $\begin{array}{l}\text { Symptoms and ill-defined conditions } \\
\text {-Convulsions } \\
\text { Accidents, poisonings and violence }\end{array}$ & $\begin{array}{l}3 \\
0 \\
0\end{array}$ & $7^{3}(2)$ & ${ }_{8}^{17}(8)$ & ${ }_{15}^{23}(12)$ \\
\hline
\end{tabular}

* The ICD disease categories are used for the purpose of the Table but the four-digit ICD codes are also available. If several complaints are present, the child is listed under the first complaint mentioned unless a complaint mentioned later appears to be of much greater importance.

\section{Cerebral palsy}

There were six children suffering from cerebral spastic infantile paralysis (ICD code 343 ). Of these, two were classified as severe, two as moderate, and two as mild, giving a rate for all severities of 0.7 per 1000 .

\section{Deafness and impairment of hearing}

When deaf mutism was included in the definition so that it comprised $I C D$ codes 388 and 389 , there were four children classified as severe or moderate who were deaf, a rate of 0.5 per 1000 . When the eight children classified as mild who had impaired hearing were also included, the rate rose to 1.4 per 1000 .

\section{Blindness}

One child was blind in both eyes (ICD code $379 \cdot 1)$ and two had congenital anomalies of the eye (cataract, code 744.3 ), giving a rate of 0.4 per 1000 children under 16.
CHARACTERISTICS OF THE SEVERELY OR MODERATELY DISABLED CHILDREN

Sex

There were more boys than girls among the children with a long-standing illness and a similar sex distribution was found in all three severity groups. The excess of boys over girls was significantly greater than that found in the whole of the GHS sample (Table 3).

Age

The proportion of children in the age group 10-15 was greater in the group of severely and moderately disabled children than in the whole of the GHS sample (Table 4). For the moderately disabled group this was partly a reflection of the way in which the severity classification was carried out, as a child who $\sigma$ had had a complaint for a long period of time was $N$ more likely to be classified as moderate. The effects $N$ of some disabling conditions also become more noticeable as a child grows older. 
Table 3 Relationship between sex and severity and comparison with all children in the GHS

\begin{tabular}{|c|c|c|c|c|c|c|c|c|c|c|}
\hline \multirow[b]{2}{*}{ Sex } & \multicolumn{2}{|c|}{ Severe } & \multicolumn{2}{|c|}{ Moderate } & \multicolumn{2}{|c|}{ Mild } & \multicolumn{2}{|c|}{$\begin{array}{l}\text { All children with a } \\
\text { long-standing illness }\end{array}$} & \multicolumn{2}{|c|}{ All children in $G H S$} \\
\hline & No. & $\%$ & No. & $\%$ & No. & $\%$ & No. & $\%$ & No. & $\%$ \\
\hline Male & 37 & 59 & 109 & 59 & 238 & 59 & 384 & 59 & 4220 & 51 \\
\hline Female & 26 & 41 & 75 & 41 & 168 & 41 & 269 & 41 & 4072 & 49 \\
\hline TOTAL & 63 & 100 & 184 & 100 & 406 & 100 & 653 & 100 & 8292 & 100 \\
\hline
\end{tabular}

All children with a long-standing illness compared with all children in GHS:

$x^{2}=17.9$

Unless otherwise stated, all results relating to the 1974 GHS sample as a whole were taken from the report on the 1974 GHS."

$\mathbf{P}<\mathbf{0 . 0 0 1}$

Table 4 Relationship between age and severity and comparison with all children in GHS.

\begin{tabular}{|c|c|c|c|c|c|c|c|c|c|c|}
\hline \multirow[b]{2}{*}{ Age group (years) } & \multicolumn{2}{|c|}{ Severe } & \multicolumn{2}{|c|}{ Moderate } & \multicolumn{2}{|c|}{ Severe and moderate } & \multicolumn{2}{|c|}{$\begin{array}{l}\text { All children with a } \\
\text { long-standing illness }\end{array}$} & \multicolumn{2}{|c|}{ All children in GHS } \\
\hline & No. & $\%$ & No. & $\%$ & No. & \% & No. & $\%$ & No. & \% \\
\hline $\begin{array}{c}0-4 \\
5-9 \\
10-15\end{array}$ & $\begin{array}{l}19 \\
17 \\
27\end{array}$ & $\begin{array}{l}30 \\
27 \\
43\end{array}$ & $\begin{array}{l}27 \\
59 \\
98\end{array}$ & $\begin{array}{l}15 \\
32 \\
53\end{array}$ & $\begin{array}{r}46 \\
76 \\
125\end{array}$ & $\begin{array}{l}19 \\
30 \\
51\end{array}$ & $\begin{array}{l}141 \\
231 \\
281\end{array}$ & $\begin{array}{l}22 \\
35 \\
43\end{array}$ & $\begin{array}{l}2369 \\
2748 \\
3175\end{array}$ & $\begin{array}{l}29 \\
33 \\
38\end{array}$ \\
\hline ALL AGES & 63 & 100 & 184 & 100 & 247 & 100 & 653 & 100 & 8292 & 100 \\
\hline
\end{tabular}

All children with a long-standing illness compared with all children in GHS:

$x^{2}=17.6$

\section{Family size}

When two-parent families were considered, more of the severely and moderately disabled children came from families containing three or more children than in the GHS sample as a whole but the difference was just non-significant at the 5\% level (Table 5).

\section{Social class}

More of the children with a long-standing illness were in the skilled manual socioeconomic groups and fewer in the professional and semiskilled manual socioeconomic groups than in the whole of the GHS sample (Table 6). When the severely and moderately disabled children were considered, the difference was more marked: $48.5 \%$ were in the skilled manual socioeconomic groups compared with $41 \cdot 3 \%$ of all children in the GHS sample.

COMPOSITION OF FAMILIES CONTAINING SEVERELY OR MODERATELY DISABLED CHILDREN

When the families which contained one or more severely or moderately disabled children were considered, the proportion of lone parents was higher than in the GHS as a whole but the difference was not found to be significant (Table 7). Although the number of lone parents in the disabled sample was very small, an analysis was carried out of the marital

Table 5 Distribution of children in two-parent families by family size and comparison with all children in GHS

\begin{tabular}{|c|c|c|c|c|c|c|}
\hline \multirow[b]{2}{*}{ Size of child's family } & \multicolumn{2}{|c|}{ Severe and moderate } & \multicolumn{2}{|c|}{$\begin{array}{l}\text { All children with a } \\
\text { long standing illness }\end{array}$} & \multicolumn{2}{|c|}{ All children in GHS* } \\
\hline & No. & \% & No. & $\%$ & No. & $\%$ \\
\hline $\begin{array}{l}2 \text { parents } 1 \text { child } \\
2 \text { parents } 2 \text { children } \\
2 \text { parents } 3 \text { children } \\
2 \text { parents } 4 \text { children } \\
2 \text { parents } 5+\text { children }\end{array}$ & $\begin{array}{l}34 \\
74 \\
58 \\
23 \\
25\end{array}$ & $\left.\begin{array}{l}16 \\
35 \\
27 \\
11 \\
12\end{array}\right\} 50$ & $\begin{array}{r}103 \\
230 \\
139 \\
65 \\
44\end{array}$ & $\left.\begin{array}{l}18 \\
40 \\
24 \\
11 \\
8\end{array}\right\} 43$ & $\begin{array}{r}1369 \\
3048 \\
1842 \\
1032 \\
580\end{array}$ & $\left.\begin{array}{l}17 \\
39 \\
23 \\
13 \\
7\end{array}\right\} 44$ \\
\hline All 2-parent families** & 214 & 100 & 581 & 100 & 7871 & 100 \\
\hline
\end{tabular}


Table 6 Distribution by social class and comparison with all children in GHS

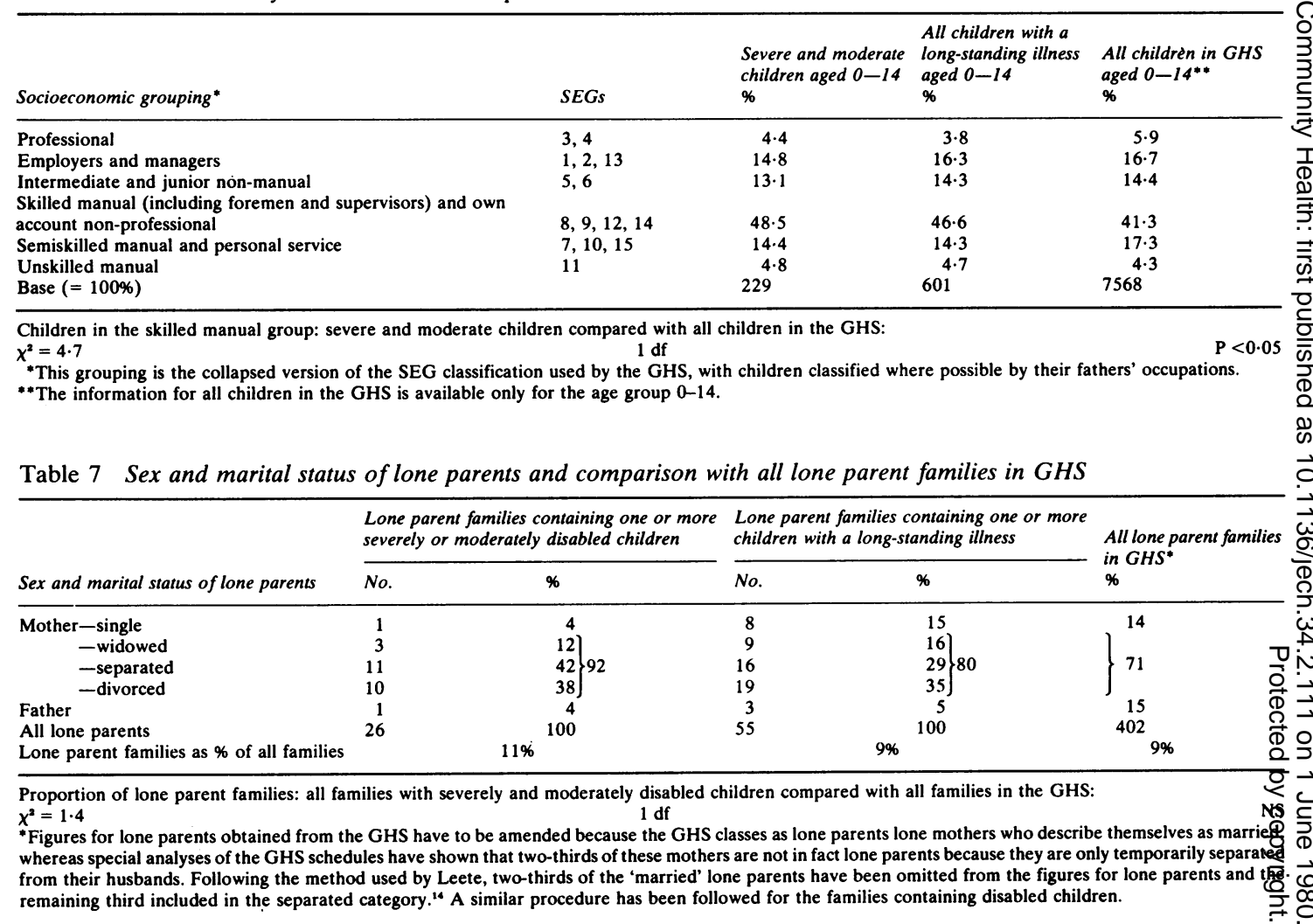

status of the lone mothers. Among the lone parent families with severely or moderately disabled children, there were fewer single mothers and lone fathers and more mothers who were widowed, separated, or divorced than among lone parent families in the GHS as a whole (Table 7).

\section{Discussion}

Data on children with a long-standing illness, disability, or infirmity were obtained from the 1974 General Household Survey and were used to produce an estimate of the prevalence rate for these chronic disorders among children of 76 per 1000 children under 16 . This rate can be compared with prevalence rates for chronic physical disorders found in other studies, although all estimates of prevalence depend on the variety of types of diseases included in the study and on the criteria of severity used to determine the inclusion of cases. The prevalence of chronic physical disorders found in the present study was 70 per 1000 children under 16 , compared with a rate of 111 per 1000 children under 16 derived by Pless and Douglas from the National Survey of Child
Health and Development, a longitudinal study of a sample of about 4700 children born in $1946 . .^{10}$ The characteristics of the two studies differed considerably, however, in that the results of the present study were based on the chronic illnesses reported by parents at the time of interview whereas past episodes of illness would have been recorded in the longitudinal study, and some clinical data were also available. The definitions of chronic illness also differed in the two studies. Prevalence rates for $\bar{D}$ chronic physical illnesses in childhood derived from $?$ cross-sectional studies and quoted by Pless and Douglas $^{10}$ ranged from 57 to 180 per 1000 . The rate of 57 per 1000 was that found in à study of 10 - to 12 -year-old Isle of Wight children which used well-defined criteria for the inclusion of cases and 9 criteria which were more selective than those used in the GHS study. ${ }^{2}$

The most common long-standing illness reported in the GHS was asthma, followed by eczema and 0 bronchitis. Asthma and eczema were also among the $N$ most common disorders found in the surveys $\mathrm{N}_{\mathrm{w}}$ mentioned above, ${ }^{210}$ but bronchitis was not included in their definitions of chronic physical disorders. 
When the children classed as severely disabled were considered, a prevalence rate of 7.6 per 1000 children under 16 was obtained $(95 \%$ confidence limits : 5.7-9.5 per 1000). This rate can be compared with the estimated prevalence rate of 7.6 per 1000 for severely handicapped children obtained for the 11-year-olds in the 1958 cohort of the National Child Development Study and with the rate of $6 \cdot 2$ per 1000 obtained for the child population of York in 1974 (estimates derived using Family Fund criteria for the definition of severe handicap ${ }^{11}$ ).

Some information on the prevalence of individual conditions is also provided by the GHS study, although the rates are based on small numbers and are subject to large sampling errors. The prevalence rate for severe mental handicap of 4.2 per 1000 children under 16 is comparable to the rate of 4 per 1000 accepted by the Department of Health and Social Security after reviewing a number of studies. ${ }^{12}$ The rate for spina bifida of $1 \cdot 1$ per 1000 children is the same as that found for 7-year-old children in the 1958 cohort of the National Child Development Study, although only half of the children who survived to the age of 7 were found to be severely disabled. ${ }^{4}$ A very low rate for the prevalence of all severities of cerebral palsy was found in the GHS study. The rate was only 0.7 per 1000 children compared with $2 \cdot 3$ per 1000 for the 7 -year-olds in the 1958 cohort and 2.9 per 1000 for children aged 5 to 14 in the Isle of Wight neurological survey. ${ }^{24}$ In the discussion on the selection of children with physical disorders for the Isle of Wight study, cerebral palsy and related conditions were mentioned as the only major group of disorders in the study that were picked out largely on the basis of a physical examination. The absence of any medical assessment in the GHS may thus contribute to the low prevalence rate for cerebral palsy.

The comparison of the results of the GHS study with those obtained from studies of applicants to the Family Fund is of interest because although the numbers of affected children in the GHS are small, the sample is nationally representative. The extent to which the applicants to the Family Fund are representative of all families with very severely disabled children is not known, although the fund provided a source of data on about 50000 such families in 1979.

The higher proportion of boys than of girls found in the GHS among the children with a long-standing illness at all levels of severity is also found in the studies on Family Fund applicants and in other studies of chronic illness in childhood. ${ }^{1013}$ As in the GHS, a higher proportion of the applicants to the Family Fund are in Social Class III M which approximates to the skilled manual socioeconomic groups $\left(52 \cdot 7 \%\right.$ of all applicants $\left.{ }^{13}\right)$.

If the influence of other factors is not taken into account, disabled children are more likely to come from large families, because such families have exposed themselves more frequently to the risk of having a disabled child. The greater prevalence of large families among the lone parent families with severely or moderately disabled children may partly explain the differences in marital status between lone mothers in these families and in the GHS as a whole. Studies on lone mothers in the GHS show that single mothers have on average the smallest number of children and divorced and separated mothers the largest. ${ }^{14}$

Children born to lone mothers appear to have a greater risk of impairment than those born in two-parent families, ${ }^{15}$ but such evidence as there is on the effect of disabled children on marriage tends to suggest that they can strengthen as well as weaken a marriage ${ }^{16}$ In this study the prevalence of one-parent families was not very different among families with disabled and non-disabled children. The data are, however, cross-sectional and provide no evidence on episodes of lone parenthood.

One of the aims of this study was to explore information on child disability obtainable from the General Household Survey which had not previously been analysed. Despite the limitations of the data, the analysis has produced findings on the prevalence of chronic sickness and disability among a nationally representative sample of the child population and on the characteristics of these disabled children.

We thank the Office of Population Censuses and Surveys for permission to analyse the data from the 1974 General Household Survey. This work was supported by a grant from the Department of Health and Social Security.

Reprints from Jane Weale, Social Policy Research Unit, Department of Social Administration and Social Work, University of York, York YO1 5DD.

\section{References}

${ }^{1}$ Harris AI. Handicapped and Impaired in Great Britain. London: HMSO, 1971.

${ }^{2}$ Rutter M, Tizard J, Whitmore K. Education, Health and Behaviour. London: Longman, 1970.

${ }^{3}$ Laurence KM, Tew BJ. Studies in spina bifida cystica IV. Arch Dis Child 1971; 47: 128-37. 
${ }^{4}$ Davie R, Butler N, Goldstein H. From Birth to Seven. London: Longman, 1972.

${ }^{5}$ Chamberlain R, Chamberlain G, Howlett B, Claireaux A. British Births 1970. Volume I. The First Week of Life. London: Heinemann, 1975.

${ }^{6}$ Bradshaw J. The Family Fund: An Initiative in Social Policy. London: Routledge and Kegan Paul, 1980.

${ }^{7}$ Weale J, Bradshaw J. The prevalence and characteristics of handicapped children: results from the 1974 General Household Survey. Social Policy Research Unit Working Paper DHSS No. 39 1/79. York: University of York, 1979.

${ }^{8}$ Office of Population Censuses and Surveys Social Survey Division. The General Household Survey 1974. London: HMSO, 1977.

${ }^{9}$ World Health Organisation. International Classification of Diseases, 8th revision. Geneva: WHO, 1967.

${ }^{10}$ Pless IB, Douglas JWB. Chronic illness in childhood: part 1. Epidemiological and clinical characteristics. Pediatrics 1971; 47: 405-14.

${ }^{11}$ Bradshaw J. Examining benefits for families with handicapped children. In: DHSS Social Security Research. London: HMSO, 1977.
${ }^{12}$ Department of Health and Social Security. Better Services for the Mentally Handicapped. London: HMSO, 1971.

${ }^{13}$ Bradshaw J, Lawton D. Some characteristics of children with severe disabilities. J Biosoc Sci 1978; 10: 107-20.

${ }^{14}$ Leete R. One-parent families: numbers and characteristics Population Trends 1978; 13: 4-9.

${ }^{15}$ Wynn M, Wynn A. The Prevention of Preterm Birth. London: Foundation for Education and Research in Child-Bearing, 1977.

${ }^{16} \mathrm{Gath} A$. The impact of an abnormal child upon the parent. Br J Psychiatry 1977; 130: 405-10.

${ }^{17}$ Duckworth D. Terminology in Relation to Disablement. Proceedings of a Conference on Occupational Disability Assessment, 1978 (unpublished paper).

${ }^{18}$ Wood PHN. Classification of Impairments and Handicaps. Geneva: World Health Organisation, 1975.

${ }^{19}$ Taylor D. Physical Impairment: Social Handicap. London: Office of Health Economics, 1977. 